This article was downloaded by: [National Taiwan University]

On: 2 April 2009

Access details: Access Details: [subscription number 908033515]

Publisher Taylor \& Francis

Informa Ltd Registered in England and Wales Registered Number: 1072954 Registered office: Mortimer House, 37-41 Mortimer Street, London W1T 3JH, UK

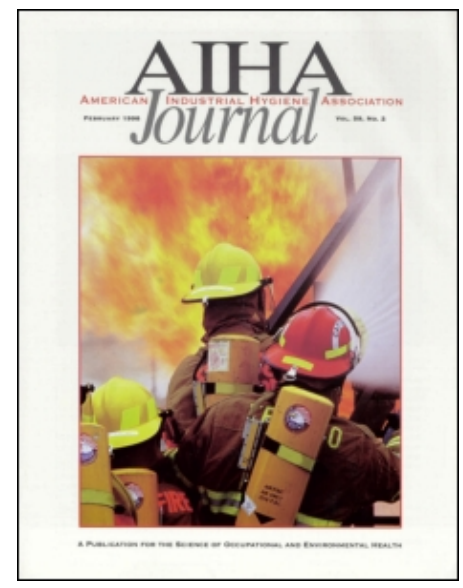

\title{
AlHA Journal
}

Publication details, including instructions for authors and subscription information:

http://www.informaworld.com/smpp/title content=t713608957

\section{Effect of Rise Distance on Droplets Generated from Bubble Bursting on the Surface of Chromic Acid Solutions}

\section{Yu-Mei Kuo a; Chiu-Sen Wang b}

a Department of Industrial Safety and Hygiene, Chung Hwa College of Medical Technology, 89 Wen-Hwa 1st St., Jen-Te Hsiang, Tainan, Taiwan. ${ }^{b}$ Department of Public Health, Graduate Institute of Environmental Health, and Graduate Institute of Occupational Medicine and Industrial Hygiene, National Taiwan University, Taipei, Taiwan.

Online Publication Date: 01 January 2002

To cite this Article Kuo, Yu-Mei and Wang, Chiu-Sen(2002)'Effect of Rise Distance on Droplets Generated from Bubble Bursting on the Surface of Chromic Acid Solutions',AlHA Journal,63:1,5 - 10

To link to this Article: DOI: 10.1080/15428110208984685

URL: http://dx.doi.org/10.1080/15428110208984685

\section{PLEASE SCROLL DOWN FOR ARTICLE}

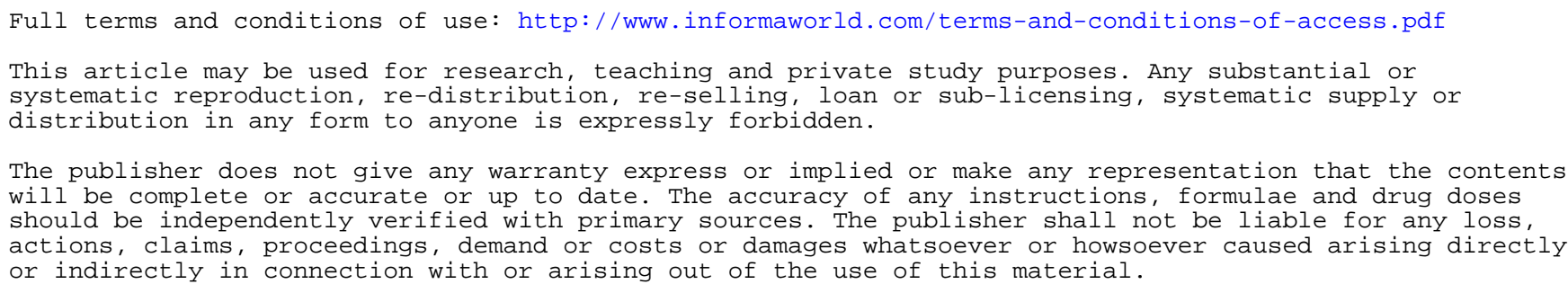




\section{AUtHORS}

Yu-Mei Kuo ${ }^{a}$ Chiu-Sen Wang

aDepartment of Industrial Safety and Hygiene, Chung Hwa College of Medical Technology, 89 Wen-Hwa lst St., Jen-Te Hsiang, Tainan, Taiwan; 'Department of Public Health, Graduate Institute of Environmental Health, and Graduate Institute of Occupational Medicine and Industrial Hygiene, National Taiwan University, Taipei, Taiwan
Funding for this study was supplied in part by Taiwan NSC grant NSC 88-2314-B-002-048.

\section{Effect of Rise Distance on Droplets Generated from Bubble Bursting on the Surface of Chromic Acid Solutions}

In the processes of chromium electroplating, bursting bubbles are the major sources of chromium droplets that may lead to nasal septum disorders among workers. The gas bubbles form as a result of electrochemical reactions on the surfaces of pieces being plated, rise through the liquid, and then burst into droplets at liquid surfaces. The dimensions of the pieces being plated differ from piece to piece, and therefore the rise distance of the bubbles varies. This study is aimed at evaluating the effect of rise distance on the characteristics of droplets generated from bubbles bursting on the surface of chromic acid solutions by an experimental bubbling system. Two rise distances, 15 and $30 \mathrm{~cm}$, were tested. An aerodynamic particle sizer was used to determine the droplet size distribution over the range of $0.8-30 \mu \mathrm{m}$. A Marple personal impactor was employed to collect droplet samples on polyvinyl chloride filters for $\mathrm{Cr}(\mathrm{VI})$ analysis. It was found that the $\mathrm{Cr}(\mathrm{VI})$ concentrations in droplets increased when the bubble rise distance increased. The result suggests that soluble ions such as $\operatorname{Cr}(\mathrm{VI})$ are scavenged by rising bubbles.

Keywords: bubbles, chromium droplets, rise distance

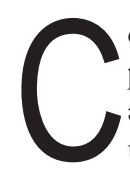
ontrol of chromium emissions is an important issue in both industrial hygiene and environmental protection. Chromium electroplating plants are the major sources of atmospheric chromium. In most chromium electroplating processes, the chromium of hexavalent form instead of trivalent form is used. Hexavalent chromium in the form of chromium trioxide, known as chromic acid, is more toxic than trivalent chromium. ${ }^{(1-5)}$

Epidemiological studies indicate that droplets containing $\mathrm{Cr}(\mathrm{VI})$ are probably the main cause for nasal septum disorders among chromium electroplating workers. Gomes ${ }^{(6)}$ studied 303 chromium electroplating workers and found $63.4 \%$ to have nasal ulceration or perforations. Lindberg and Hedenstierna ${ }^{(7)}$ examined 100 chromium electroplating workers and 119 unexposed controls with reference to changes in the nasal septum. They found that more than twothirds of the subjects had developed nasal septum ulceration and perforation.

In Taiwan, chromium droplets generated from electroplating processes have received considerable attention because of high prevalence rates of nasal septum ulcer or perforation among workers. Lin et al. ${ }^{(8)}$ conducted a survey of 7 chromium electroplating factories and examined 79 workers with reference to nasal septum lesions. They found 16 cases of nasal septum perforation and 42 with ulceration. In a separate study, Liu et al. ${ }^{(9)}$ found 5 with nasal septum perforation among 45 hard chrome-electroplating workers.

In the chromium electroplating process, chromium droplets are generated from bubbles bursting at liquid surfaces. Generation of droplets from bursting bubbles is of great importance in the liquid-to-air transfer of nonvolatile compounds, which may have adverse effects on the environment and human health. Previous studies on the transfer of trace metals from seawater to air showed that oceanic droplets were enriched with trace metals. Van Grieken et al. ${ }^{(10)}$ performed bubbling experiments by using radioactive tracers of metals such as ${ }^{65} \mathrm{Zn}$ and ${ }^{75} \mathrm{Se}$. Their 


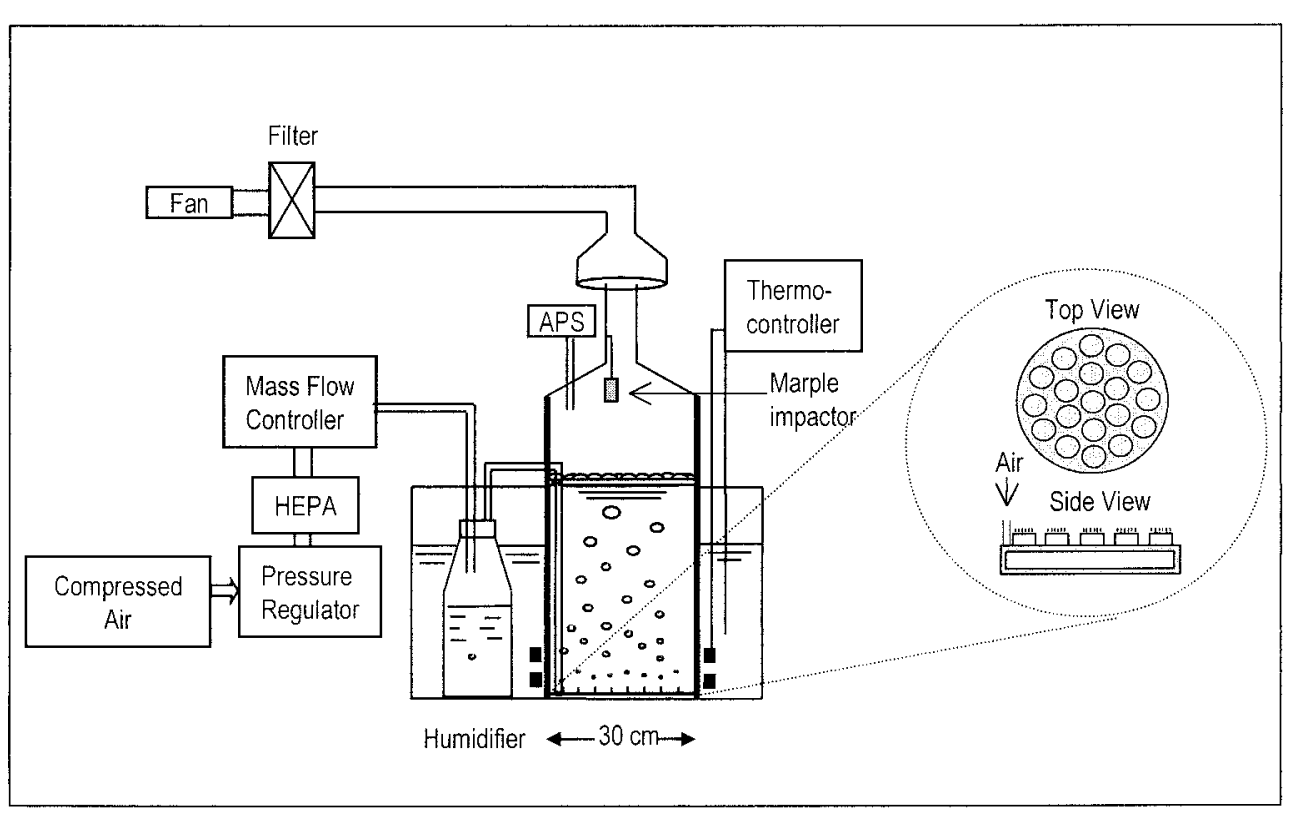

FIGURE 1. Schematic diagram of the experimental system

study confirmed that the composition of resulting droplets differed from that of the bulk solution. Piotrowicz et al.(11) found that trace metals in water could be highly concentrated in droplets generated through bursting of bubbles and suggested that factors such as scavenging by rising bubbles, adsorption in the surface layer, and biological processes may relate to the enrichment of these metals in droplets. However, these previous studies dealt with only dilute solutions. Little is known regarding the transfer of ions from concentrated solutions to air by the bursting of bubbles, which occurs in many industrial operations.

Data on the characteristics of $\mathrm{Cr}(\mathrm{VI})$-containing droplets generated from bursting bubbles are needed in the control of chromium emissions and the assessment of health risk. In a practical operation the rise distance of bubbles varies because of the diverse dimensions of the pieces being plated and could have some influence on the droplet characteristics. The objective of this study, therefore, was to evaluate the effect of rise distance on the characteristics of $\mathrm{Cr}(\mathrm{VI})$-containing droplets by an experimental bubbling system. The characteristics of droplets studied included the number size distribution, the volume distribution, and the $\mathrm{Cr}(\mathrm{VI})$ concentration in droplets.

\section{MATERIALS AND METHOD}

$\mathrm{T}$ wo concentrations of chromic acid solution, 31.25 and $125 \mathrm{~g} /$ $\mathrm{L}$, were used in this study. The change in $\mathrm{Cr}(\mathrm{VI})$ concentration in the bulk solution measured before and after each run was within $5 \%$ (in a range of 0.5 to $4.8 \%$ ) even though water evaporated from the liquid surface during the bubbling process.

The experimental system, shown schematically in Figure 1, consisted of a glass cylindrical tank, a water bath, a bubbling system, and the droplet sampling/measuring instruments.

A glass cylinder, $50 \mathrm{~cm}$ in height, was used to load the test solution for experiments. The cylindrical tank, $28.6 \mathrm{~cm}$ in inner diameter, was sufficiently large that the wall effect on the size of generated bubbles could be neglected. The tank was kept in a water bath to maintain the liquid temperature in the tank at $45^{\circ}$, the average temperature of electroplating solutions in practical applications. ${ }^{(4)}$ The outer wall of the tank was covered with a thermal jacket and, as a result, the air temperature inside the tank was about $37^{\circ}$. The humidity inside the tank was near saturation during the experiments.

The bubbling system consisted of 19 circular caps, each containing 19 glass capillaries of $0.2 \mathrm{~mm}$ in inner diameter and 3.2 $\mathrm{cm}$ length. The circular caps, made of polypropylene, were $3.5 \mathrm{~cm}$ in diameter. The glass capillaries were inserted into the caps, which had inside surfaces lined with a silicone pad to prevent gas leakage. The plastic caps were then mounted onto an acrylic chamber and placed at the bottom of the cylindrical tank. The bubbling system was similar to those used by Wangwongwatana et al. ${ }^{(12)}$ and Pilacinski et al. ${ }^{(13)}$

The sparging air was obtained from a laboratory air supply, and its flow rate was regulated by a mass flow controller. The air passed through a HEPA filter and a humidifier and then entered the bubbling system, where the air passed through the acrylic chamber and emerged from the capillaries. Sparging air through the $\mathrm{CrO}_{3}$ solution in the tank led to formation of droplets above the liquid surface.

An aerodynamic particle sizer (APS, model 3310, TSI, St. Paul, Minn.) was employed to measure the number concentration and size distribution of droplets. A Marple personal impactor (model 290, Graseby Andersen, Atlanta, Ga.) was used to collect sizefractionated droplet samples for analysis of $\mathrm{Cr}(\mathrm{VI})$.

The impactor had eight stages with aerodynamic cutoff diameters of $0.6 ; 1 ; 1.5 ; 3.5 ; 6 ; 10 ; 15$; and $21 \mu \mathrm{m}$ at a sampling flow rate of $2 \mathrm{~L} / \mathrm{min}$. Droplets of various size ranges were collected on PVC filters, and the $\mathrm{Cr}(\mathrm{VI})$ concentration in each sample was determined by chemical analysis.

Limited by the height of the glass tank, only two bubble rise distances, 15 and $30 \mathrm{~cm}$, were studied. An acrylic column was added on the top of the tank to provide a sampling height of 35 $\mathrm{cm}$, and the outer part of the column was insulated with a thermal jacket to prevent heat loss. 


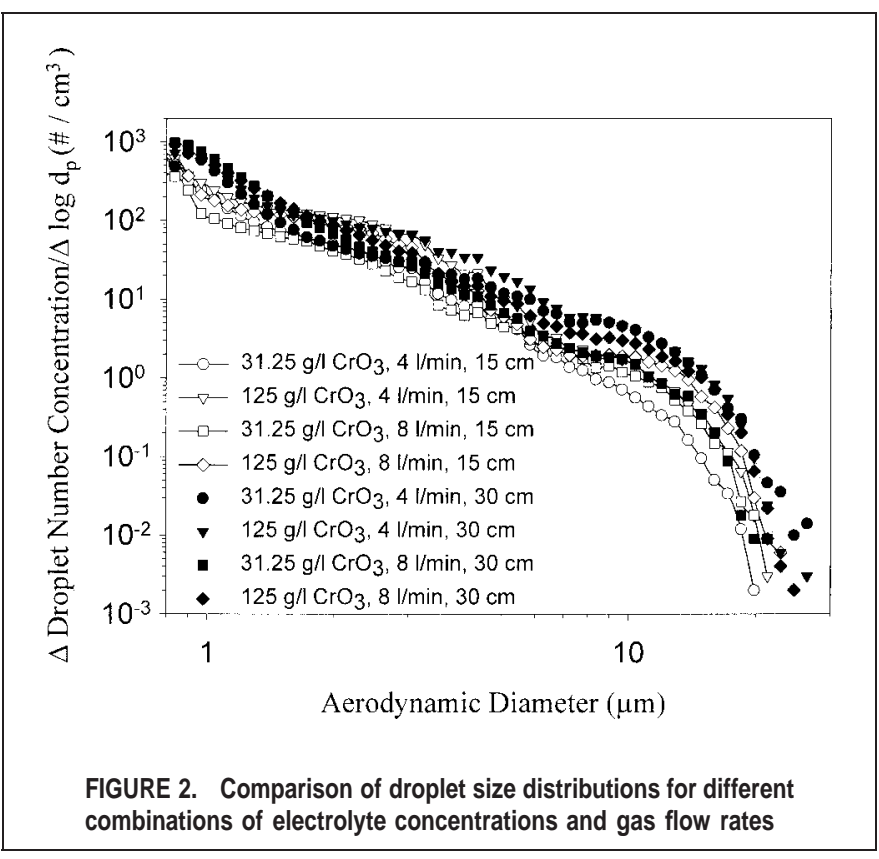

In each run, the chromic acid solution of a given concentration was prepared with deionized distilled water and then heated to $45^{\circ}$ in a storage container that was kept in a temperature-controlled water bath. Filtered and humidified air was then introduced into the bubbling system at a given flow rate. Subsequently, the electrolyte solution was gradually transferred to the bubbling tank by a peristaltic pump (model 505S, Watson Marlow, Falmouth, U.K.) until the liquid height reached 15 or $30 \mathrm{~cm}$ above the capillary openings. Airborne droplets were sampled by an impactor for a duration of $2 \mathrm{hr}$. The number concentration of droplets was measured by the APS three times during the bubbling period of each run.

The U.S. National Institute for Occupational Safety and Health method 7600, developed primarily for measuring chromic acid concentrations, was used to determine the $\mathrm{Cr}(\mathrm{VI})$ concentration in each droplet sample. After sampling, each PVC filter was extracted by a few milliliters of $0.5 \mathrm{~N} \mathrm{H}_{2} \mathrm{SO}_{4}$ for 5 to $10 \mathrm{~min}$, and then $0.5 \mathrm{~mL}$ of s-diphenylcarbazide solution was added to the extract solution. The total volume of the solution was brought to $5 \mathrm{~mL}$ with $0.5 \mathrm{~N} \mathrm{H}_{2} \mathrm{SO}_{4}$. The absorbance of the color complex was measured at $540 \mathrm{~nm}$ by an ultraviolet-visible (UV-VIS) recording spectrophotometer with a light path of $1 \mathrm{~cm}$ (model UV160A, Shimadzu Corp., Japan).

The detection limit of the spectrophotometer was $1.8 \mathrm{ng} / \mathrm{mL}$ (equivalent to $9 \mathrm{ng} / \mathrm{m}^{3}$ for a $0.24 \mathrm{~m}^{3}$ air sample). Recovery of $\mathrm{Cr}(\mathrm{VI})$ sampled on a filter was experimentally determined by using a spiked aqueous solution of potassium dichromate deposited on a PVC filter. The recovery at 1 and $10 \mu \mathrm{g}$ concentration levels was $97 \pm 3 \%$ and $95 \pm 3 \%$, respectively, within $15 \mathrm{hr}$ after spiking.

\section{RESULTS AND DISCUSSION}

\section{Droplet Volume Distributions}

The droplet volume distribution was calculated from the number distribution data obtained for all experimental conditions by the APS. Figure 2 shows the number distributions of droplets produced from bursting bubbles for various experimental conditions including the two concentrations of 31.25 and $125 \mathrm{~g} / \mathrm{L} \mathrm{CrO}$,

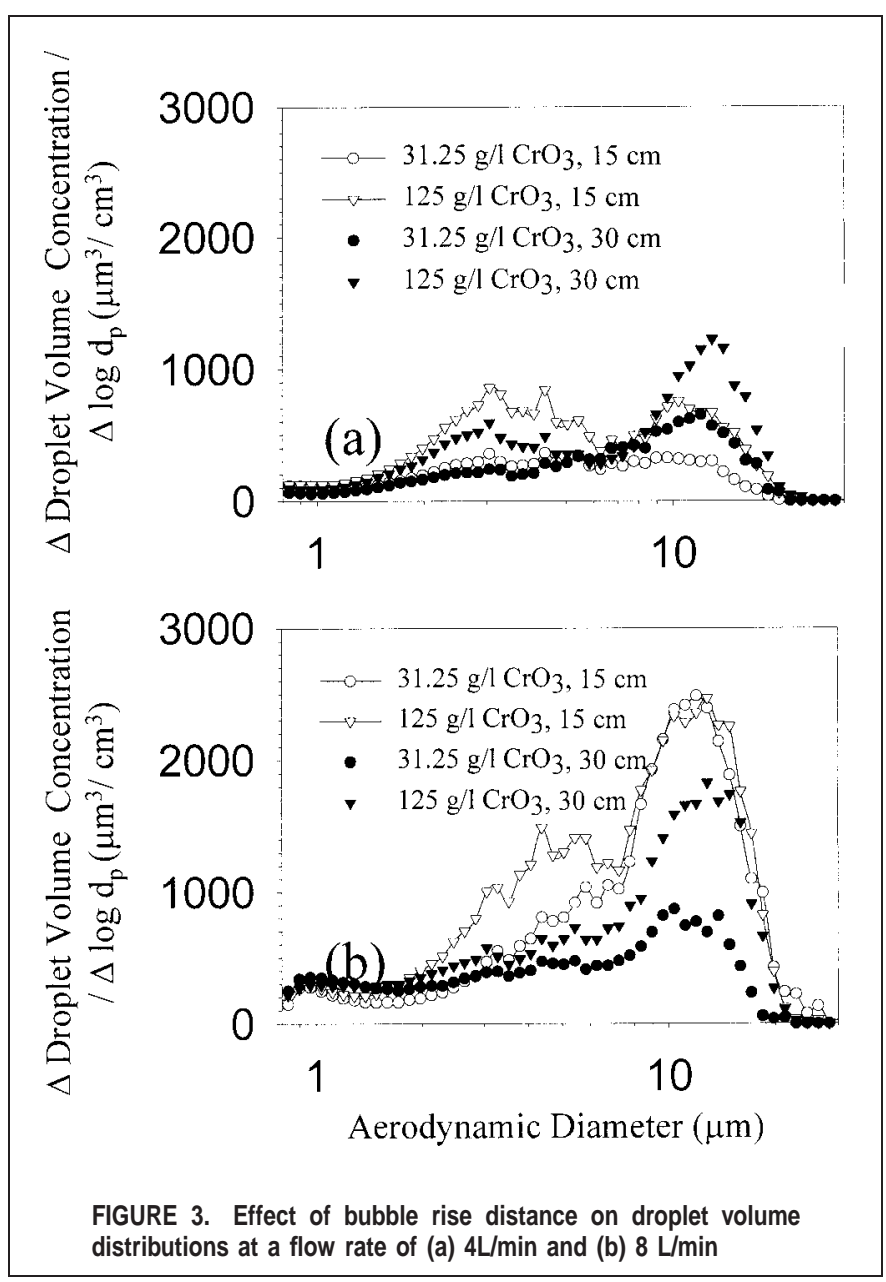

two gas flow rates of 4 and $8 \mathrm{~L} / \mathrm{min}$, and two bubble rise distances of 15 and $30 \mathrm{~cm}$.

The APS gave the droplet size in aerodynamic diameter, which was converted into physical diameter by the following formula:

$$
d_{a}=d_{v}\left[\frac{\rho_{p} C\left(d_{v}\right)}{\rho_{0} C\left(d_{a c}\right) \chi}\right]^{1 / 2}
$$

where $d_{a}$ is the aerodynamic diameter, $d_{v}$ the equivalent volume diameter, $\rho_{\mathrm{p}}$ the droplet density, $\rho_{0}$ the unit density $\left(1 \mathrm{~g} / \mathrm{cm}^{3}\right), \mathrm{C}$ the Cunningham slip correction, and $\chi$ the dynamic shape factor. The droplet density was assumed to be identical to the density of the bulk solution. Both the Cunningham slip correction factor and the dynamic shape factor are 1 for relatively large spherical droplets measured in this study.

The droplet volume concentration in a given size interval was determined by multiplying the volume of a droplet with the geometric mean diameter by the number concentration in a given size interval $\left(\pi \mathrm{d}_{\mathrm{g}}{ }^{3} \mathrm{~N} / 6\right.$, where $\mathrm{d}_{\mathrm{g}}$ is the geometric mean diameter and $\mathrm{N}$ the number concentration of droplets in a given size range).

Figure 3 shows that the change in bubble rise distance had a negligible influence on the volume distributions of both film and jet droplets when the gas flow rate was $4 \mathrm{~L} / \mathrm{min}$, whereas the influence became significant at a higher gas flow rate of $8 \mathrm{~L} / \mathrm{min}$.

According to the results of a previous study, ${ }^{(14)}$ the film droplets and jet droplets have a dividing diameter of $7 \mu \mathrm{m}$. The effect of bubble rise distance on the volume concentration of droplets in the following three groups for the two rise distances are plotted in Figure 4: (a) the total droplets (larger than $0.8 \mu \mathrm{m}$ ), (b) the 


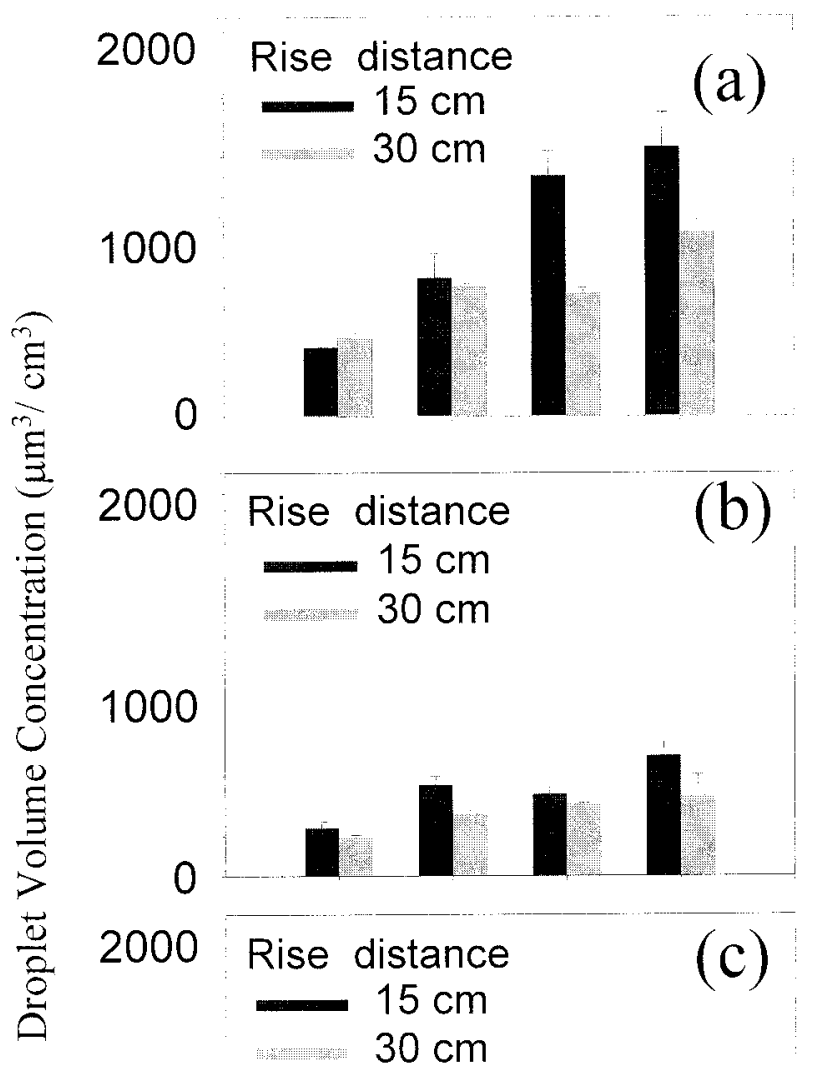

1000

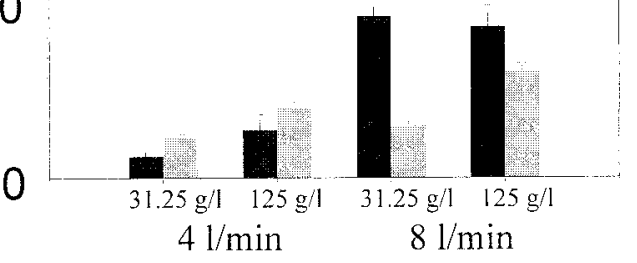

Electrolyte Concentration

and gas flow rate

FIGURE 4. Effect of bubble rise distance on the volume concentrations of droplets in three size intervals: (a) larger than $0.8 \mu \mathrm{m}$, (b) in the size range of 0.8 to $7 \mu \mathrm{m}$, and (c) larger than $7 \mu \mathrm{m}$, for different combinations of electrolyte concentrations and gas flow rates. Each bar represents the mean of three replicates and an error bar represents one standard deviation.

film droplets $(0.8$ to $7 \mu \mathrm{m})$, and (c) the jet droplets (larger than $7 \mu \mathrm{m})$. The droplet volume concentration decreased by $30-50 \%$ as the bubble rise distance increased from 15 to $30 \mathrm{~cm}$ for a gas flow rate of $8 \mathrm{~L} / \mathrm{min}$ in 31.25 and $125 \mathrm{~g} / \mathrm{L} \mathrm{CrO}_{3}$ solutions. The decrease in volume concentration can be attributed to reduction in the production of jet droplets as the bubble rise distance increased.

\section{Size-Fractionated $\mathrm{Cr}(\mathrm{VI})$ Concentrations in Droplets}

The sampling efficiency of the Marple personal impactor with respect to particle size has been experimentally investigated by $\mathrm{Ru}-$ bow et al. ${ }^{(15)}$ and Rader et al. ${ }^{(16)}$ An efficiency of nearly $100 \%$ was found for $10-\mu \mathrm{m}$ particles, whereas the sampling efficiency decreased to about $80 \%$ for particles larger than $21 \mu \mathrm{m}$. The $\mathrm{Cr}(\mathrm{VI})$ mass distributions obtained in this study were all bimodal with a mode at a diameter larger than $10 \mu \mathrm{m}$ and another at about 3-5 $\mu \mathrm{m}$. The mode of the $\mathrm{Cr}(\mathrm{VI})$ mass distribution of film droplets in this study is in good agreement with that found by Pegnam and Pilat. ${ }^{(17)}$ Using a University of Washington Mark 20 cascade impactor to collect droplets in the exhausting duct of a chromic acid anodizing tank, Pegnam and Pilat found that the $\mathrm{Cr}(\mathrm{VI})$ mass distribution was unimodal with a mass median aerodynamic diameter of about $4 \mu \mathrm{m}$ in the measured aerodynamic size range of $0.05-24 \mu \mathrm{m}$.

In general, the $\mathrm{Cr}(\mathrm{VI})$ mass distributions were comparable in shape to the corresponding droplet volume distributions for all the measurements in the size range of $0.8-20 \mu \mathrm{m}$ for which the APS can give measurements with good precision.

Figure 5 shows that, at a gas flow rate of $4 \mathrm{~L} / \mathrm{min}$, an increase in bubble rise distance generally led to an increase in airborne $\mathrm{Cr}(\mathrm{VI})$ concentration in the following three size intervals of droplets: (a) larger than $0.8 \mu \mathrm{m}$, (b) 0.8 to $7 \mu \mathrm{m}$ (mainly film droplets), and (c) larger than $7 \mu \mathrm{m}$ (mainly jet droplets). For a gas flow rate of $8 \mathrm{~L} / \mathrm{min}$, there is no marked effect of bubble rise distance. According to the results shown in Figures 4 and 6, an increase in rise distance led to a decrease in droplet volume concentration and an increase in $\mathrm{Cr}(\mathrm{VI})$ concentration in droplets. The airborne $\mathrm{Cr}(\mathrm{VI})$ concentration is a function of droplet volume concentration and $\mathrm{Cr}(\mathrm{VI})$ concentration in droplets, and therefore is influenced by the rise distance in a complicated way. Because of the limited data obtained in the present study, it remains unclear why the airborne $\mathrm{Cr}(\mathrm{VI})$ concentration of film and jet droplets changed in different directions as the bubble rise distance increased. A more comprehensive investigation on the effect of rise distance on droplet characteristics is needed to explain the observations.

\section{$\mathrm{Cr}(\mathrm{VI})$ Concentration in Droplets}

The $\mathrm{Cr}(\mathrm{VI})$ concentration in droplets is of great importance in the assessment of health effects. Previous studies ${ }^{(10,11,18-21)}$ showed a fractionation effect of ions in droplets generated from bursting bubbles.

The $\mathrm{Cr}(\mathrm{VI})$ concentration in droplets was calculated by dividing the airborne $\mathrm{Cr}(\mathrm{VI})$ concentration by the droplet volume concentration in a given size interval. Only the $\mathrm{Cr}(\mathrm{VI})$ concentration in the droplets of 1 to $10 \mu \mathrm{m}$ in aerodynamic diameter was calculated, because the APS may gradually underestimate the droplets beyond $10 \mu \mathrm{m}$ and the volume distribution mode of film droplets was mainly in this size range.

Figure 6 shows the effect of bubble rise distance on $\mathrm{Cr}(\mathrm{VI})$ concentration in droplets of $1-10 \mu \mathrm{m}$ in aerodynamic diameter. The $\mathrm{Cr}(\mathrm{VI})$ concentration in droplets produced at $30-\mathrm{cm}$ rise distance solution was generally higher than that at $15-\mathrm{cm}$ rise distance. The difference is attributable to the scavenging effect of a rising bubble, one of the major mechanisms suggested for ion enrichment (defined as the concentration ratio of other metal ion to sodium ion) in oceanic droplets generated from bursting bubbles by Van Grieken et al., (10) Piotrowicz et al., ${ }^{(11)}$ and MacIntyre. ${ }^{(20)}$

As the rise distance of bubbles in $31.25 \mathrm{~g} / \mathrm{L} \mathrm{CrO}_{3}$ solution increased from 15 to $30 \mathrm{~cm}$, the $\mathrm{Cr}(\mathrm{VI})$ concentration in droplets generated at a gas flow rate of $8 \mathrm{~L} / \mathrm{min}$ increased more than the increase at $4 \mathrm{~L} / \mathrm{min}$. However, the $\mathrm{Cr}(\mathrm{VI})$ concentration in droplets increased by a factor of about 2 when the bubble rise distance 


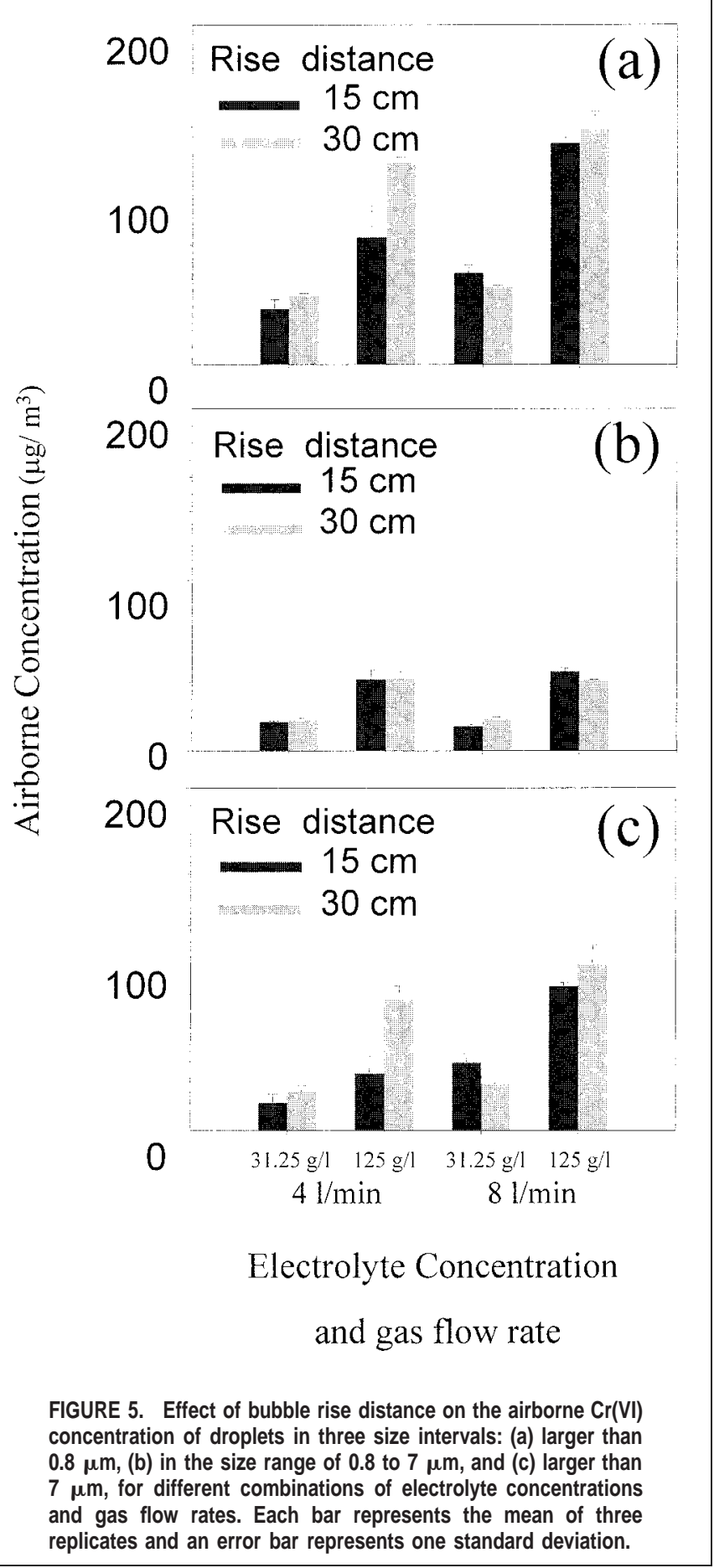

increased from 15 to $30 \mathrm{~cm}$ at gas flow rates of 4 and $8 \mathrm{~L} / \mathrm{min}$ in $125 \mathrm{~g} / \mathrm{L} \mathrm{CrO}_{3}$ solution. One possible explanation is that the $\mathrm{Cr}(\mathrm{VI})$ ions in droplets generated at a gas flow rate of $4 \mathrm{~L} / \mathrm{min}$ in $31.25 \mathrm{~g} / \mathrm{L} \mathrm{CrO}_{3}$ solution were nearly saturated and therefore the ions remained at about the same concentration as the rise distance increased.

\section{CONCLUSIONS}

$\mathbf{F}$ or the ranges of experimental parameters studied, the following conclusions can be made.

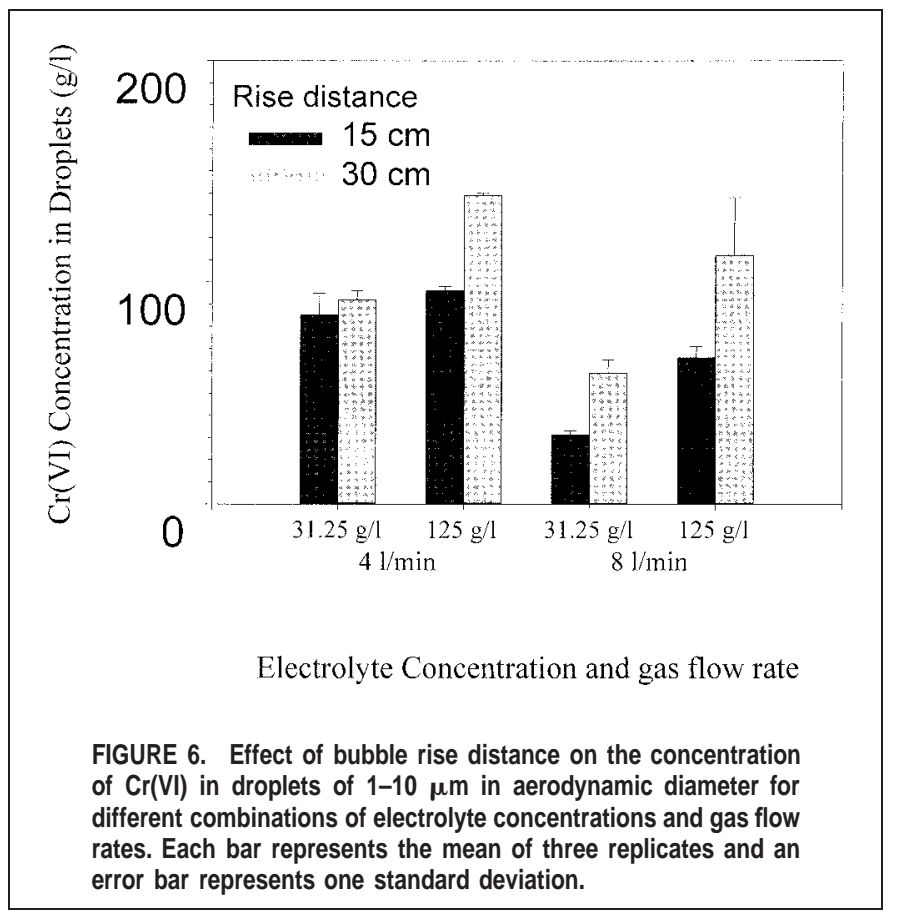

(1) Droplets generated from bursting of bubbles on the surface of electrolyte solutions were predominately in the submicron range. The count median diameter of droplets was in the range of 0.16 $0.24 \mu \mathrm{m}$ in the measured size range of $0.1-30 \mu \mathrm{m}$.

(2) The droplet volume distribution calculated from the number distribution data was bimodal, indicating the presence of both film and jet droplets that had a volume distribution mode of 3-5 $\mu \mathrm{m}$ and more than $10 \mu \mathrm{m}$, respectively. An increase in bubble rise distance led to a reduction in droplet volume concentration.

(3) The Cr (VI) concentration in the resulting droplets increased as the bubble rise distance increased.

The present study provided data on droplet size distributions, airborne $\mathrm{Cr}(\mathrm{VI})$ mass concentrations, and droplet volume concentrations that should have applications in health risk assessment of chromium droplets and control of chromium emission in electroplating or anodizing processes. The chromium emission can be expressed in terms of airborne $\mathrm{Cr}(\mathrm{VI})$ concentration used in this study and is a function of droplet volume concentration and $\mathrm{Cr}(\mathrm{VI})$ concentration in droplets.

\section{REFERENCES}

1. Dubpernell, G.: Modern electroplating. In A.G. Gray, editor, Chromium: The Chromium Plating Process. New York: John Wiley \& Sons, 1953. p. 135.

2. Graham, A.K.: Plating Bath Compositions and Operating Conditions. In A.K. Graham, editor, Electroplating Engineering Handbook, 3rd ed. New York: Van Nostrand Reinhold, 1971. p. 231.

3. Sitting, M.: Electroplating and Related Metal Finishing: Pollutant and Toxic Materials Control. Park Ridge, NJ: Noyes Data Corp., 1978. p. 58.

4. Zaki, N.: Risk reduction in chromium emissions. Metal Finishing 88: 99-102 (1990).

5. Burgess, W.A.: Recognition of Health Hazards in Industry: A Review of Materials and Processes, 2nd ed. New York: John Wiley \& Sons, 1995.

6. Gomes, E.R.: Incidence of chromium induced diseases among electroplating workers in Brazil. Ind. Med. 41(12):21-25 (1972). 
7. Lindberg, E., and G. Hedenstierna: Chrome plating: Symptoms, findings in the upper airways, and effects on lung function. Arch. Environ. Health 38:367-374 (1983).

8. Lin, S.C., C.C. Tai, C.C. Chan, and J.D. Wang: Nasal septum lesions caused by chromium exposure among chromium electroplating workers. Am. J. Ind. Med. 26:221-228 (1994).

9. Liu, C.S., J.H. Lai, C.W. Kuo, T.I. Lin, and C.H. Lai: Nasal septum diseases in chromium electroplating workers in Central Taiwan. J. Occup. Safety Health 2(3):25-35 (1994)(in Chinese).

10. Van Grieken, R.E., T.B. Johansson, and J.W. Winchester: Trace metal fractionation effects between sea water and aerosols from bubble bursting. J. Rech. Atmos. 12:611-620 (1974).

11. Piotrowicz, S.R., R.A. Duce, J.L. Fasching, and C.P. Weisel: Bursting bubbles and their effect on the sea-to-air transport of $\mathrm{Fe}, \mathrm{Cu}$ and Zn. Marine Chem. 7:307-324 (1979).

12. Wangwongwatana, S., P.V. Scarpino, K. Willeke, and P.A. Baron: System for characterizing aerosols from bubbling liquids. Aerosol Sci. Technol. 13:297-307 (1990).

13. Pilacinski, W., M.J. Pan, K.W. Szewczyk, M. Lehtimaki, and K. Willeke: Aerosol released from aerated broths. Biotechnol. Bioeng. 36: 970-973 (1990).

14. Kuo, Y.M., and C.S. Wang: Concentration effect of chromic acid solutions on the enrichment of $\mathrm{Cr}(\mathrm{VI})$ in droplets from bursting bubbles. Aerosol Sci. Technol. 31:275-285 (1999).

15. Rubow, K.L., V.A. Marple, J. Olin, and M.A. McCawley: A personal cascade impactor: Design, evaluation and calibration. Am. Ind. Hyg. Assoc. J. 48:532-538 (1987).

16. Rader, D.J., L.A. Mondy, J.E. Brockmann, D.A. Lucero, and K.L. Rubow: Stage response calibration of the Mark III and Marple personal cascade impactors. Aerosol Sci. Technol. 14:365-379 (1991).

17. Pegnam, R.C., and M.J. Pilat: Airborne particulate emissions from a chromic acid anodizing process tank. J. Air Waste Manage. Assoc. 42:303-308 (1992).

18. Bloch, M.R., D. Kaplan, V. Kertes, and J. Schnerb: Ion separation in bursting bubbles: An explanation for the irregular ion ratios in atmospheric precipitations. Nature 209:802-803 (1966).

19. MacIntyre, F., and J.W. Winchester: Phosphate ion enrichment in drops from breaking bubbles. J. Phys. Chem. 73:2163-2169 (1969).

20. MacIntyre, F.: Geochemical fractionation during mass transfer from sea to air by breaking bubbles. Tellus 22:451-461 (1970).

21. Wilkniss, P.E., and D.J. Bressan: Fractionation of the elements F, $\mathrm{Cl}, \mathrm{Na}$, and $\mathrm{K}$ at the sea-air interface. J. Geophys. Chem. 77:53075315 (1972). 